J Health Commun. 2010 ; 15(Suppl 2): 159-171. doi:10.1080/10810730.2010.499982.

\title{
Uncertainty About Advance Care Planning Treatment Preferences Among Diverse Older Adults
}

\author{
Rebecca L. Sudore, MD ${ }^{1,2}$, Dean Schillinger, $\mathbf{M D}^{2,3}$, Sara J. Knight, PhD $^{1,4}$, and Terri R. \\ Fried, MD ${ }^{5,6}$ \\ ${ }^{1}$ Veterans Affairs Medical Center, San Francisco, California, USA \\ ${ }^{2}$ Department of Medicine University of California, San Francisco, California, USA \\ ${ }^{3}$ UCSF Center for Vulnerable Populations, San Francisco General Hospital, San Francisco, \\ California, USA \\ ${ }^{4}$ Department of Psychiatry and Urology, University of California, San Francisco, California, USA \\ ${ }^{5}$ Veterans Affairs Connecticut Healthcare System, Hartford, Connecticut, USA \\ ${ }^{6}$ Yale University, New Haven, Connecticut, USA
}

\begin{abstract}
The complexities associated with advance treatment decisions may result in decisional uncertainty and poorly informed choices, particularly among vulnerable populations such as minorities and patients with limited health literacy. Using a hypothetical scenario, we assessed uncertainty about treatment preferences among 205 chronically-ill, English/Spanish-speaking older adults from a county outpatient clinic in San Francisco. Participants were read a scenrio that described a very poor health state and poor outcome of life support treatment. Participants were asked to imagine that they were in this scenario and to choose either: all life support (LS) treatments; try LS with an option of stopping; or no LS. They were then asked how certain they were about this decision. Forty five percent of participants were uncertain about their decision. In adjusted multivariate analysis, Latinos and Asian/Pacific Islanders were more likely than Whites to be uncertain about their treatment decisions as were participants with limited versus adequate literacy and poor versus good self-rated health. Many patients may be uncertain about advance treatment preferences. Culturally sensitive, literacy-appropriate tools are needed to address decisional uncertainty and to help patients prepare for decision making about their future health care.
\end{abstract}

\section{Keywords}

advance care planning; health literacy; decision making; vulnerable populations

Corresponding author: Rebecca.Sudore@ucsf.edu, San Francisco VA Medical Center, 4150 Clement Street, \#151R, San Francisco, CA 94121, Phone: 415-221-4810 x 23475.

CONFLICT OF INTEREST STATEMENT:

Dr. Sudore is funded in part by the Pfizer Foundation through the Clear Health Communication Fellowship. The Pfizer foundation was not involved in the design, acquisition of data, analysis, interpretation of the results, or the writing of this manuscript. No other authors report a conflict of interest. 


\section{INTRODUCTION}

Advance care planning encourages patients to make treatment decisions in advance of serious illness and decisional incapacity. These decisions usually focus on whether patients would want to receive life-sustaining treatments for end-of-life care, such as mechanical ventilation, in the event of a medical crisis. Advance treatment decisions are often difficult because they require patients to project their preferences into the future and fully appreciate unknown health states (Ditto, Jacobson, Smucker, Danks, \& Fagerlin, 2006; Halpern \& Arnold, 2008; Koch, 2001). For example, patients are often asked to consider health states they have never experienced such as: "If I am in a coma..." (Emanuel, Barry, Stoeckle, Ettelson, \& Emanuel, 1991) "If you were to become so sick you may die soon..."(Sudore, et al., 2007) "Imagine you have severe dementia" (Pearlman, Starks, Cain, \& Cole, 2005). Decisional uncertainty may reflect patients' lack of understanding of the clinical situation and/or indecision about their preferences for care. Therefore, decisional uncertainty may be an important indicator of the need for further clarification of patients' understanding and values before an advance decision can be used to guide clinical care.

Prior studies have demonstrated that patients with limited health literacy and African Americans have high rates of decisional uncertainty about making advance treatment decisions (Allen, Allen, Hilgeman, \& DeCoster, 2008; Volandes, Barry, Chang, \& PaascheOrlow, 2009). Limited health literacy has been defined as having difficulty obtaining, processing, and understanding basic health information in order to make appropriate healthcare decisions (Institute of Medicine. Health literacy: A Prescription to End Confusion., 2004). Patients with limited health literacy, henceforth referred to as limited literacy, often do not fully understand their disease processes and have greater difficulty weighing the risks and benefits of treatment (Davis, Williams, Marin, Parker, \& Glass, 2002; Fagerlin, Ubel, Smith, \& Zikmund-Fisher, 2007; Schillinger, et al., 2003; Williams, Baker, Parker, \& Nurss, 1998). Furthermore, among some racial/ethnic minorities, specifically African Americans and Latinos, there may be mistrust of the medical establishment due to historical events or experiential health-related disparities (Crawley, 2002; Smith, Sudore, \& Perez-Stable, 2009). These patients may have difficulty trusting medical information and being certain about their healthcare choices.

To our knowledge, the study of race/ethnicity and decisional uncertainty for advance care planning has been limited to Whites and African Americans and has not included Latinos and Asian/Pacific Islanders. Furthermore, because literacy and race/ethnicity are highly correlated, (Paasche-Orlow, Parker, Gazmararian, Nielsen-Bohlman, \& Rudd, 2005) studies have not examined whether both contribute independently to decisional uncertainty. Therefore, our objectives were: 1) to examine the prevalence of uncertainty concerning advance decisions about life sustaining treatment among chronically-ill, racially/ethnically diverse older adults with varying levels of health literacy; and 2) to assess the associations between literacy and race/ethnicity with decisional uncertainty, hypothesizing that low literacy and minority status would each be independently associated with uncertainty. 


\section{METHODS}

\section{Participants}

This descriptive study included general medicine outpatients from a county hospital in San Francisco, known to have high rates of chronic illness (Sudore, et al., 2007). Participants were recruited through convenience sampling between August and December 2004 and were eligible if they were 50 years of age or older and reported speaking English or Spanish "well/very well" (Sudore, et al., 2007). Patients were excluded if they were deaf, delirious, too ill to participate as determined by their physician, or if they had cognitive impairment as determined with the Mini-Cog (Borson, Scanlan, Chen, \& Ganguli, 2003).

\section{Design}

Participants were read a hypothetical scenario in English or Spanish by native-speaking research assistants (Table 1). This took approximately 30-40 seconds. The scenario described serious illness and a poor outcome of life sustaining treatment (Table 1). Subjects were asked to imagine they were in this situation, but were reassured that the scenario did not pertain to their personal health.

\section{Measures}

Our primary outcome measure was uncertainty about treatment preferences (Table 1). To minimize uncertainty, the hypothetical scenario was constructed to represent an extreme in which the current health state was poor and there was a high likelihood of a poor outcome of treatment. The scenario was also constructed to minimize known contributors to decisional uncertainty such as asking participants to make judgments about treatment outcomes that are difficult to predict and/or to interpret probabilistic risk/benefit information (Fagerlin, et al., 2007). Prior to being asked about uncertainty, participants were asked to choose which of the following would best describe the care they would prefer if faced with the hypothetical scenario: "all life support treatments;" "try life-support treatments, but to stop if they are not helping after a short period of time;" "to just be kept comfortable and not have any lifesupport treatments;" or "I don't know." We considered participants who responded "I don't know" as not having made a treatment choice. For participants who made a treatment choice, we asked, "How sure are you about the choice you just made: very sure, somewhat sure, not so sure, or not sure at all?" Because serious clinical decisions are often based on these pre-specified decisions, a high bar was set - certainty was defined as "very sure" while uncertainty was defined as being only "somewhat sure", "not so sure", or "not sure at all". We also created a certainty score (1-4 points), with higher points indicating more certainty.

Our main independent predictors were literacy and self-reported race/ethnicity. Literacy was measured using the short form Test of Functional Health Literacy in Adults (s-TOFHLA, scores 0-36) which has been well-validated in diverse, Spanish-speaking populations (correlation coefficients with other literacy assessments exceed 0.74) (Parker, Baker, Williams, \& Nurss, 1995). In bi-variate analysis, this variable was categorized as inadequate literacy (scores 0-16), marginal (scores 17-22) and adequate (scores 23-36) (Baker, Williams, Parker, Gazmararian, \& Nurss, 1999). Bi-variate results demonstrated a threshold effect, such that uncertainty was equally common among participants with inadequate and 
marginal compared to adequate literacy (Table 3). Therefore, for multivariate analysis, we dichotomized literacy into adequate versus limited (score $\leq 22$, marginal plus inadequate). We also obtained self-reported age, language (native English, Spanish, or English as a second language), gender, income, educational attainment, and, as a measure of acculturation, whether patients were born outside of the U.S. Because the following variables may affect treatment preferences and certainty, (Belcher, Fried, Agostini, \& Tinetti, 2006; Ditto, et al., 2006; Forrow, 1994; Johnson, Elbert-Avila, \& Tulsky, 2005) we also obtained self-reported religiosity (very-to-extremely versus somewhat-to-not at all), selfrated health status (fair-to-poor versus good-to-excellent), trust in doctors to honor medical wishes (agree/disagree), and prior exposure to end-of-life experiences, (defined as having completed an advance directive, having helped another person complete an advance directive, or any previous personal or family/friend admission to an ICU). We created a composite measure of prior exposure based on affirmative responses to any exposure indicators.

\section{Data Analysis}

Percentages and means were used to describe the study population. Bi-variate associations between participant characteristics and uncertainty were determined with $\chi 2$ tests for the dichotomous uncertainty variable and t-tests for the certainty score. Associations were also assessed using multivariate logistic regression with the dichotomous uncertainty variable. Literacy and race/ethnicity were included a priori in the multivariate models. Age was also included as a potential confounder, as were other variables if they were associated with uncertainty in bi-variate analysis, $\mathrm{P}<.20$. Three multivariate models were created to assess the independent effects of literacy and other confounding variables except race/ethnicity (Model 1), race/ethnicity and other confounding variables except literacy (Model 2), and both literacy and race/ethnicity in the same adjusted model (Model 3). For Model 3, we also performed a sensitivity analysis whereby we included participants who reported "I don't know" about their treatment preferences into the uncertain category. Because $98 \%$ of Latinos spoke Spanish and because $80 \%$ of Asian/Pacific Islanders spoke English as a second language, to address multi-collinearity, only ethnicity, and not language, was included in the models. Because $90 \%$ of Latinos and $100 \%$ of Asian/Pacific Islanders were born outside of the U.S., only race-ethnicity, and not acculturation, was included in the models.

\section{RESULTS}

The mean age of participants was 61 years; $25 \%$ self-reported being White, $31 \%$ Latino, 24\% African American, 9\% Asian/Pacific Islander, and 10\% multi-racial/ethnic or other; and $40 \%$ had limited literacy. Fifty three percent of participants were women, 32\% had not completed high school, $40 \%$ were born outside of the U.S., and $69 \%$ had fair-to-poor selfrated health. In response to the scenario, $20 \%$ of participants preferred all life support treatments, $28 \%$ preferred to try life support but stop if not working, $45 \%$ preferred no life support, and 7\% did not know (Table 2).

Of the 198 (96\%) participants who made a treatment choice, 55\% stated they were "very sure" about their choice. Of the $45 \%$ reporting some degree of uncertainty about their 
treatment choice, $32 \%$ stated they were "somewhat sure", $8 \%$ were "not so sure", and 5\% were "not sure at all". The mean certainty score was $3.4 \pm .75$ (with 4 representing "very sure”).

In bi-variate analyses, (Table 3) patients with inadequate (60\%) and marginal literacy (62\%) were more likely to be uncertain compared to patients with adequate literacy $(34 \%, \mathrm{p}=.001)$. Asian/Pacific Islanders (74\%) and Latinos (61\%) were more likely to be uncertain compared to African Americans (37\%) and Whites (31\%), p<.001). Uncertainty was also more common among participants who spoke English as a second language (83\%) and among Spanish-speakers (63\%) compared to English-speakers (38\%, p=.001); participants with < high school versus more education ( $55 \%$ vs. $41 \%, \mathrm{p}=.05$ ); participants born outside of the U.S versus in the U.S. (67\% vs. $30 \%, \mathrm{p}<.001)$; and participants with fair-to-poor versus good-to-excellent health $(51 \%$ vs. $32 \%, \mathrm{p}=.01)$. Uncertainty was not associated with treatment preferences. Bivariate results examining certainty scores demonstrated identical associations with patient characteristics (results not shown).

After adjusting for confounding variables other than race/ethnicity (Model 1), limited versus adequate literacy was associated with uncertainty (Table 4). After adjusting for confounding variables other than literacy, being Latino or Asian/Pacific Islander versus White was associated with uncertainty. When both literacy and race/ethnicity were included in adjusted multivariate models (Model 3), having limited versus adequate literacy (AOR 2.11; 95\% CI: 1.03-4.33) or being Latino (AOR 2.50; 95\% CI: 1.01-6.16) or Asian/Pacific Islander (AOR 4.25 ; 95\% CI: $1.22-14.76)$ versus White remained independently associated with decisional uncertainty. The magnitude of these associations did not change appreciably between models. In all models, having fair-to-poor versus good-to-excellent health was also associated with uncertainty (Model 3: AOR 2.11; 95\% CI 1.04-4.28). Being African American was not associated with uncertainty. These results were unchanged after sensitivity analysis.

\section{DISCUSSION}

Close to half (45\%) of older, chronically ill, diverse patients with varying levels of health literacy were uncertain about advance treatment decisions in response to a hypothetical scenario depicting a poor baseline health state and a very poor outcome of treatment. Uncertainty was associated with having limited compared to adequate literacy, being Latino or Asian/Pacific Islander as compared to being White, and with having poor compared to good self-rated health. The scenario used to assess uncertainty was constructed to reduce known contributors to uncertainty and to minimize ambiguity about the hypothetical health state or the outcome of treatment. Even so, the rate of uncertainty was high. In scenarios constructed to reflect the realities of clinical decision making - where the outcome of treatment frequently cannot be predicted in advance and patients need to consider probabilistic information - we might expect uncertainty to be greater.

A prior study examining uncertainty about advance decisions for end-stage dementia found that being African American versus White and having lower literacy was associated with uncertainty. However, this study did not assess the independent effects of literacy and race/ 
ethnicity concurrently or assess other race/ethnic groups (Volandes, Barry, et al., 2009).

Another study assessing race/ethnicity (African American and Whites) and not literacy, also showed that many African American patients have uncertainty concerning decisions about life support preferences in response to scenarios based on Alzheimer's disease, emphysema, and cancer (Allen, et al., 2008). It is unclear why we did not observe similar differences between African Americans and Whites. In the Volandes study, (Volandes, Barry, et al., 2009) 60\% of African Americans had limited literacy compared to only $33 \%$ of African Americans in our sample. It is possible that the greater range of literacy scores allowed us to better observe the independent associations between literacy, race/ethnicity, and uncertainty. There are credible reasons for uncertainty among African Americans including mistrust and perceived racism resulting in poor self-efficacy and confidence in making medical decisions (Gamble, 1997; Gordon, Street, Sharf, \& Souchek, 2006; Moody-Ayers, Stewart, Covinsky, $\&$ Inouye, 2005). Therefore, it is possible there are regional differences, and that our results are not generalizable to other African American populations, or that we did not have the power to detect an association.

To our knowledge, no prior study has studied nor demonstrated that Latinos and/or Asian/ Pacific Islanders have more decisional uncertainty than Whites. Our results suggest that acculturation and language may play a role. The vast majority (89\% and 100\%) of the Latino and Asian/Pacific Islander participants in our sample were born outside of the U.S., compared with only $8 \%$ of Whites, $2 \%$ of African Americans, and 5\% of Multi-racial ethnic/ Other participants. Acculturation and cultural differences have been shown to affect patients' trust in the medical establishment, knowledge of end-of-life issues, and preferences for treatment and autonomous versus family decision making (Kwak \& Haley, 2005; Smith, et al., 2009). In addition, $30 \%$ of our study participants were Spanish-speaking and $80 \%$ of Asian/Pacific Islanders spoke English as a second language. Limited English proficiency has been shown to be associated with poor patient-clinician communication and with confusion about medical information - factors which may have contributed to uncertainty in our study population (Sudore, et al., 2009).

The uncertainty observed among patients with limited literacy may reflect a lack of appropriate clinical information to make decisions, an inability to identify one's healthrelated values (such as what brings life meaning), uncertainty about how to apply values to a specific medical decision, or a lack of knowledge about the issues faced at the end-of-life. These explanations for uncertainty are plausible because patients with limited literacy often do not understand their disease processes, their healthcare choices, or how to weigh the risks and benefits of treatment (Davis, et al., 2002; Fagerlin, et al., 2007; Schillinger, et al., 2003; Williams, et al., 1998). In addition, patients with limited literacy have difficulty obtaining medical information to make informed choices and often lack the self-efficacy to ask questions about their healthcare (Dubow, 2004; Katz, Jacobson, Veledar, \& Kripalani, 2007; Peters, Hibbard, Slovic, \& Dieckmann, 2007; Schillinger, Bindman, Wang, Stewart, \& Piette, 2004). Furthermore, although we attempted to minimize ambiguity, decisional uncertainty may have resulted from the way in which the scenario was framed (Allen, Phillips, Pekmezi, Crowther, \& Prentice-Dunn, 2009; Prentice-Dunn, McMath, \& Cramer, 2009), because patients with limited literacy have been shown to be particularly susceptible to framing effects (Fagerlin, et al., 2007). 
When decisional uncertainty results from the lack of information to make informed decisions and/or patients' inability to identify their preferences, it can be an important indicator of the need for further clarification of patients' understanding and values before an advance decision can be used to guide clinical care. Video images and literacy-appropriate end-of-life decision aids focused on treatment outcomes can ameliorate the effects of race/ ethnicity and limited literacy on decisional uncertainty (Allen, et al., 2008; Volandes, Ariza, Abbo, \& Paasche-Orlow, 2008; Volandes, Barry, et al., 2009). The responsiveness of decisional uncertainty to health education materials highlights the need for continued work developing culturally sensitive, literacy appropriate decision support tools to prepare patients and to support them through the decision making process.

In this study, participants with poor self-rated health status were more likely to be uncertain. This finding suggests that another major source of uncertainty may be an accurate evaluation of the inherent uncertainty and complexities of medical decision making (Ditto, et al., 2006; Halpern \& Arnold, 2008; Koch, 2001). Some have suggested that if patients are fully informed of the consequences of their decisions, it is expected, and perhaps desired, for patients to have increased decisional uncertainty (McNutt, 2004). Patients' health preferences also change with changes in health status as demonstrated in prior research (Ditto, et al., 2006; Fried, et al., 2006; Lockhart, Ditto, Danks, Coppola, \& Smucker, 2001) and described by Prospect Theory (Winter, Lawton, \& Ruckdeschel, 2003). Therefore, uncertainty may reflect patients' experiences with changes in health status over time and the corresponding observations of their own changing values and goals for health care. The prior studies demonstrating decreases in uncertainty with educational interventions about treatment options (Allen, et al., 2008; Volandes, Barry, et al., 2009; Volandes, PaascheOrlow, et al., 2009) have included, at most, only $36 \%$ of participants with fair-to-poor health compared to the $69 \%$ of participants in our sample. It is unclear if education about treatment options alone would decrease uncertainty in patients with poor health status, especially if uncertainty is based on an accurate assessment of decline in health and change in one's values. Rather, for these patients, studies suggest that discussing the potential for adaptation to changing health states, values, and preferences can help patients better identify their preferences for care (Ubel, Loewenstein, \& Jepson, 2005).

In order for clinicians to respond appropriately to patients' sources of uncertainty and to tailor their advance care planning decisional support, they should not only ask patients about their treatment preferences, but explore whether and why patients are uncertain. Asking these questions can help clinicians determine an individual patient's specific sources of uncertainty and respond with the appropriately tailored intervention. Furthermore, understanding patients' decisional uncertainty, and the reasons behind it, may also help clinicians and surrogate decision makers better interpret advance treatment decisions and ensure that these decisions represent fully informed and deeply considered values and goals for care.

Limitations of this study include recruiting participants from only one site which may limit the generalizability of our results. In addition, we cannot disentangle the uncertainty participants reported about their treatment preferences and the confusion they may have had about the scenario or the way in which the study questions were asked. Within the clinical 
encounter, clinicians may use their own phrasing to describe hypothetical scenarios which may increase or decrease decisional uncertainty. Furthermore, our estimates of uncertainty may be conservative because, rather than being given a written advance directive with hypothetical scenarios to complete on their own - as is often the case in clinical practice the scenario was read to participants verbatim by bilingual research assistants. It is also important to note that decisions made in a research setting are very different from those made in the clinical context. It may be that if patients had the opportunity to discuss their own clinical context with their clinicians, family, and social supports, as it pertains to the hypothetical scenario, their uncertainty may have been minimized.

\section{Conclusion}

The goal of advance care planning is to honor patients' wishes for care at the end-of-life. However, inherent uncertainty about future, unknown clinical situations makes advance decision making complex. This study demonstrates that uncertainty about advance treatment preferences based on hypothetical scenarios is common and that patients with limited literacy, Latinos and Asian/Pacific Islanders, and patients with poor health status are more likely to be uncertain about their choices for healthcare. Some aspects of uncertainty are inherent to end-of-life decision making and may be more fully appreciated by patients with poor health status. However, among patients with limited literacy and minorities, uncertainty due to a poorly informed choice may be ameliorated through literacy-appropriate decision support interventions. By assessing patients' uncertainty at the time of advance decision making, clinicians can identify those patients that may need more decisional support or education. In addition, taking uncertainty into account at the time an advance treatment decision is made could help clinicians and surrogate decision makers ensure that these decisions represent fully informed and deeply considered values and goals for care.

\section{Acknowledgments}

Dr. Sudore and this study were supported by a VA Career Development Award and a Pfizer Fellowship in Clear Health Communication; Dr. Schillinger was supported by an NIH Clinical and Translational Science Award UL1 RR024131; Dr. Knight is supported by the VHA Health Services Research Service Program to Improve Care for Veterans with Complex Comorbid Conditions (REA-01-097); and Dr. Fried is supported by a K24 AG028443.

\section{References}

Allen RS, Allen JY, Hilgeman MM, DeCoster J. End-of-life decision-making, decisional conflict, and enhanced information: race effects. J Am Geriatr Soc. 2008; 56(10):1904-1909. [PubMed: 18775035]

Allen RS, Phillips LL, Pekmezi D, Crowther MR, Prentice-Dunn S. Living Well with Living Wills: Application of Protection Motivation Theory to Living Wills Among Older Caucasian and African American Adults. Clin Gerontol. 2009; 32(1):44-59. [PubMed: 19337566]

Baker DW, Williams MV, Parker RM, Gazmararian JA, Nurss J. Development of a brief test to measure functional health literacy. Patient Educ Couns. 1999; 38(1):33-42. [PubMed: 14528569]

Belcher VN, Fried TR, Agostini JV, Tinetti ME. Views of older adults on patient participation in medication-related decision making. J Gen Intern Med. 2006; 21(4):298-303. [PubMed: 16686804]

Borson S, Scanlan JM, Chen P, Ganguli M. The Mini-Cog as a screen for dementia: validation in a population-based sample. J Am Geriatr Soc. 2003; 51(10):1451-1454. [PubMed: 14511167]

Crawley LM. Palliative care in African American communities. J Palliat Med. 2002; 5(5):775-779. [PubMed: 12572983] 
Davis TC, Williams MV, Marin E, Parker RM, Glass J. Health literacy and cancer communication. CA Cancer J Clin. 2002; 52(3):134-149. [PubMed: 12018928]

Ditto PH, Jacobson JA, Smucker WD, Danks JH, Fagerlin A. Context changes choices: a prospective study of the effects of hospitalization on life-sustaining treatment preferences. Med Decis Making. 2006; 26(4):313-322. [PubMed: 16855121]

Dubow J. Adequate literacy and health literacy: prerequisites for informed health care decision making. Issue Brief (Public Policy Inst (Am Assoc Retired Pers)). 2004; (IB70):1-11.

Emanuel LL, Barry MJ, Stoeckle JD, Ettelson LM, Emanuel EJ. Advance directives for medical care-a case for greater use. N Engl J Med. 1991; 324(13):889-895. [PubMed: 2000111]

Fagerlin A, Ubel PA, Smith DM, Zikmund-Fisher BJ. Making numbers matter: present and future research in risk communication. Am J Health Behav. 2007; 31(Suppl 1):S47-56. [PubMed: 17931136]

Forrow L. The green eggs and ham phenomena. Hastings Cent Rep. 1994; 24(6):S29-32. [PubMed: 7860277]

Fried TR, Byers AL, Gallo WT, Van Ness PH, Towle VR, O’Leary JR, et al. Prospective study of health status preferences and changes in preferences over time in older adults. Arch Intern Med. 2006; 166(8):890-895. [PubMed: 16636215]

Gamble VN. Under the shadow of Tuskegee: African Americans and health care. Am J Public Health. 1997; 87(11):1773-1778. [PubMed: 9366634]

Gordon HS, Street RL Jr, Sharf BF, Souchek J. Racial differences in doctors' information-giving and patients' participation. Cancer. 2006; 107(6):1313-1320. [PubMed: 16909424]

Halpern J, Arnold RM. Affective forecasting: an unrecognized challenge in making serious health decisions. J Gen Intern Med. 2008; 23(10):1708-1712. [PubMed: 18665428]

Institute of Medicine. Health literacy: A Prescription to End Confusion. Washington DC: National Academic Press; 2004.

Johnson KS, Elbert-Avila KI, Tulsky JA. The influence of spiritual beliefs and practices on the treatment preferences of African Americans: a review of the literature. J Am Geriatr Soc. 2005; 53(4):711-719. [PubMed: 15817022]

Katz MG, Jacobson TA, Veledar E, Kripalani S. Patient literacy and question-asking behavior during the medical encounter: a mixed-methods analysis. J Gen Intern Med. 2007; 22(6):782-786. [PubMed: 17431697]

Koch T. Future states: the axioms underlying prospective, future-oriented, health planning instruments. Soc Sci Med. 2001; 52(3):453-465. [PubMed: 11330779]

Kwak J, Haley WE. Current research findings on end-of-life decision making among racially or ethnically diverse groups. Gerontologist. 2005; 45(5):634-641. [PubMed: 16199398]

Lockhart LK, Ditto PH, Danks JH, Coppola KM, Smucker WD. The stability of older adults' judgments of fates better and worse than death. Death Stud. 2001; 25(4):299-317. [PubMed: 11803982]

McNutt RA. Shared medical decision making: problems, process, progress. Jama. 2004; 292(20): 2516-2518. [PubMed: 15562133]

Moody-Ayers SY, Stewart AL, Covinsky KE, Inouye SK. Prevalence and correlates of perceived societal racism in older african-american adults with type 2 diabetes mellitus. J Am Geriatr Soc. 2005; 53(12):2202-2208. [PubMed: 16398910]

Paasche-Orlow MK, Parker RM, Gazmararian JA, Nielsen-Bohlman LT, Rudd RR. The prevalence of limited health literacy. J Gen Intern Med. 2005; 20(2):175-184. [PubMed: 15836552]

Parker RM, Baker DW, Williams MV, Nurss JR. The test of functional health literacy in adults: a new instrument for measuring patients' literacy skills. J Gen Intern Med. 1995; 10(10):537-541. [PubMed: 8576769]

Pearlman RA, Starks H, Cain KC, Cole WG. Improvements in advance care planning in the Veterans Affairs System: results of a multifaceted intervention. Arch Intern Med. 2005; 165(6):667-674. [PubMed: 15795344]

Peters E, Hibbard J, Slovic P, Dieckmann N. Numeracy skill and the communication, comprehension, and use of risk-benefit information. Health Aff (Millwood). 2007; 26(3):741-748. [PubMed: 17485752] 
Prentice-Dunn S, McMath BF, Cramer RJ. Protection motivation theory and stages of change in sun protective behavior. J Health Psychol. 2009; 14(2):297-305. [PubMed: 19237497]

Schillinger D, Bindman A, Wang F, Stewart A, Piette J. Functional health literacy and the quality of physician-patient communication among diabetes patients. Patient Educ Couns. 2004; 52(3):315323. [PubMed: 14998602]

Schillinger D, Piette J, Grumbach K, Wang F, Wilson C, Daher C, et al. Closing the loop: physician communication with diabetic patients who have low health literacy. Arch Intern Med. 2003; 163(1):83-90. [PubMed: 12523921]

Smith AK, Sudore RL, Perez-Stable EJ. Palliative care for Latino patients and their families: whenever we prayed, she wept. JAMA. 2009; 301(10):1047-1057. E1041. [PubMed: 19278947]

Sudore RL, Landefeld CS, Barnes DE, Lindquist K, Williams BA, Brody R, et al. An advance directive redesigned to meet the literacy level of most adults: A randomized trial. Patient Educ Couns. 2007; 69(1-3):165-195. [PubMed: 17942272]

Sudore RL, Landefeld CS, Perez-Stable EJ, Bibbins-Domingo K, Williams BA, Schillinger D. Unraveling the relationship between literacy, language proficiency, and patient-physician communication. Patient Educ Couns. 2009; 75(3):398-402. [PubMed: 19442478]

Ubel PA, Loewenstein G, Jepson C. Disability and sunshine: can hedonic predictions be improved by drawing attention to focusing illusions or emotional adaptation? J Exp Psychol Appl. 2005; 11(2): 111-123. [PubMed: 15998183]

Volandes AE, Ariza M, Abbo ED, Paasche-Orlow M. Overcoming educational barriers for advance care planning in latinos with video images. J Palliat Med. 2008; 11(5):700-706. [PubMed: 18588401]

Volandes AE, Barry MJ, Chang Y, Paasche-Orlow MK. Improving Decision Making at the End of Life with Video Images. Med Decis Making. 2009

Volandes AE, Paasche-Orlow MK, Barry MJ, Gillick MR, Minaker KL, Chang Y, et al. Video decision support tool for advance care planning in dementia: randomised controlled trial. BMJ. 2009; 338:b2159. [PubMed: 19477893]

Williams MV, Baker DW, Parker RM, Nurss JR. Relationship of functional health literacy to patients' knowledge of their chronic disease. A study of patients with hypertension and diabetes. Arch Intern Med. 1998; 158(2):166-172. [PubMed: 9448555]

Winter L, Lawton MP, Ruckdeschel K. Preferences for prolonging life: a prospect theory approach. Int J Aging Hum Dev. 2003; 56(2):155-170. [PubMed: 14533855] 


\section{Table 1}

\section{Hypothetical Scenario}

I'm going to ask you to imagine what it would be like if your doctor told you some very bad news about your health. Imagine your doctor told you that you have a serious disease that does not have a cure and that you may die within the next 6 months. Then imagine you get very sick and have to go to the hospital. You and your doctor have to decide what to do.

Your doctor thinks that life-support treatments are NOT LIKELY to help you live longer and will not cure your serious disease.

Life support treatments are those treatments given by doctors to try and keep patients alive. Some examples of life support treatments are: shocks to the heart, pressing on the chest to keep the heart pumping, or a tube placed in the lungs to help with breathing.

Even though the life support treatments will not cure your serious disease and you may still die soon, would you still want the treatments if your doctor thought they were NOT LIKELY to help you live longer? 


\section{Table 2}

PATIENT CHARACTERISTICS, $\mathrm{n}=205$

\begin{tabular}{|c|c|}
\hline & $\%$ or mean $( \pm \mathrm{SD})$ \\
\hline Age & 61 years $( \pm 8)$ \\
\hline Women & 53 \\
\hline \multicolumn{2}{|l|}{ Race/Ethnicity } \\
\hline White, Non-Hispanic & 25 \\
\hline White, Hispanic (Latino) & 31 \\
\hline African American, Non-Hispanic & 24 \\
\hline Asian & 9 \\
\hline Multi-racial/ethnic, Other & 10 \\
\hline \multicolumn{2}{|l|}{ Literacy (s-TOFHLA scores range 0-36) } \\
\hline Marginal (s-TOFHLA scores 16-22) & 18 \\
\hline Inadequate (s-TOFHLA scores $\leq 15$ ) & 22 \\
\hline \multicolumn{2}{|l|}{ Language } \\
\hline English & 62 \\
\hline Spanish & 30 \\
\hline English is a second language & 8 \\
\hline Income $<\$ 10,000 / \mathrm{yr}$ & 49 \\
\hline Less than high school education & 32 \\
\hline Born outside of the U.S. & 40 \\
\hline Fair to poor self-rated health & 69 \\
\hline Very to extremely religious & 46 \\
\hline Prior exposure to end-of-life experiences (overall) & 76 \\
\hline Previously filled out an advance directive & 13 \\
\hline Helped others fill out an advance directive & 13 \\
\hline Previously admitted to ICU & 42 \\
\hline Had friends/family admitted to ICU & 64 \\
\hline Distrust doctors to honor medical wishes & 13 \\
\hline \multicolumn{2}{|l|}{ Life Support Treatment Preferences based on scenario } \\
\hline All life support treatments & 20 \\
\hline Try life support, but stop if not working & 28 \\
\hline No life support treatments & 45 \\
\hline Do not know & 7 \\
\hline
\end{tabular}


Table 3

\section{PATIENT CHARACTERISTICS ASSOCIATED WITH BEING UNCERTAIN ABOUT TREATMENT PREFERENCES}

\begin{tabular}{|c|c|c|}
\hline Patient Characteristics & Uncertain about Preferences \% & P-value \\
\hline \multicolumn{3}{|l|}{ Treatment Preferences Based on the Scenario } \\
\hline All life support treatments, $n=40$ & 48 & .35 \\
\hline Try life support, but stop if not working, $\mathrm{n}=58$ & 48 & \\
\hline No life support treatments $n=93$ & 38 & \\
\hline \multicolumn{3}{|l|}{ Age } \\
\hline $50-54$ years, $\mathrm{n}=51$ & 39 & .67 \\
\hline $55-58$ years, $\mathrm{n}=53$ & 43 & \\
\hline $59-65$ years, $n=52$ & 51 & \\
\hline $66-91$ years, $n=49$ & 47 & \\
\hline \multicolumn{3}{|l|}{ Gender } \\
\hline Women & 50 & .14 \\
\hline Men & 40 & \\
\hline \multicolumn{3}{|l|}{ Race/Ethnicity: } \\
\hline White, Non-Hispanic, $n=51$ & 31 & $<.001$ \\
\hline White, Hispanic (Latino), $\mathrm{n}=64$ & 61 & \\
\hline African American, Non-Hispanic, $n=49$ & 37 & \\
\hline Asian, $n=19$ & 74 & \\
\hline Multi-racial/ethnic/Other, $n=21$ & 24 & \\
\hline \multicolumn{3}{|l|}{ Literacy } \\
\hline Inadequate, $\mathrm{n}=45$ & 60 & .001 \\
\hline Marginal, $\mathrm{n}=37$ & 62 & \\
\hline Adequate, $n=123$ & 34 & \\
\hline \multicolumn{3}{|l|}{ Language } \\
\hline English is a second language, $\mathrm{n}=18$ & 83 & $<.001$ \\
\hline Spanish, $\mathrm{n}=60$ & 63 & \\
\hline English, $n=145$ & 31 & \\
\hline \multicolumn{3}{|l|}{ Income } \\
\hline$\leq \$ 10,000 /$ year & 47 & .24 \\
\hline$>\$ 10,000 /$ year & 38 & \\
\hline \multicolumn{3}{|l|}{ Education: } \\
\hline$<$ High school education, $\mathrm{n}=66$ & 55 & .05 \\
\hline$\geq$ High school education, $\mathrm{n}=139$ & 41 & \\
\hline \multicolumn{3}{|l|}{ Acculturation status } \\
\hline Born outside of the U.S., $n=82$ & 67 & $<.001$ \\
\hline Born in the U.S., $\mathrm{n}=122$ & 30 & \\
\hline \multicolumn{3}{|l|}{ Health Status } \\
\hline Fair-to-poor, n=142 & 51 & .01 \\
\hline Good-to-excellent, $n=63$ & 32 & \\
\hline
\end{tabular}




\begin{tabular}{lcc}
\hline Patient Characteristics & Uncertain about Preferences $\%$ & P-value \\
\hline Religious & 41 & .30 \\
Very to extremely religious, $\mathrm{n}=93$ & 49 & \\
Not at all to somewhat, $\mathrm{n}=111$ & & .53 \\
Prior exposure to end-of-life experiences & 44 & \\
Yes, $\mathrm{n}=156$ & 49 & .65 \\
No, $\mathrm{n}=49$ & & \\
Distrust doctors to honor medical wishes & 41 & \\
Yes, $\mathrm{n}=27$ & 45 & \\
No, $\mathrm{n}=177$ & &
\end{tabular}




\section{Table 4}

Multivariate Results of the Association between Literacy and Race/ethnicity with Uncertainty*

\begin{tabular}{|l|c|c|c|}
\hline Variables $^{\dagger}$ & $\begin{array}{c}\text { Model 1 } \\
\text { Literacy alone } \\
\text { AOR (95\% CI) }\end{array}$ & $\begin{array}{c}\text { Model 2 } \\
\text { Race/ethnicity alone } \\
\text { AOR (95\% CI) }\end{array}$ & $\begin{array}{c}\text { Model 3 } \\
\text { Literacy + race/ethnicity } \\
\text { AOR (95\% CI) }\end{array}$ \\
\hline Limited Literacy & $2.60(1.31-5.14)$ & - & $2.11(1.03-4.33)$ \\
\hline Race/Ethnicity & - & & \\
\hline White, Hispanic (Latino) & & $2.77(1.14-6.73)$ & $2.50(1.02-6.16)$ \\
\hline African American & & $1.17(0.50-2.73)$ & $1.08(0.45-2.55)$ \\
\hline Asian/Pacific Islander & & $5.42(1.61-18.30)$ & $4.25(1.22-14.76)$ \\
\hline Multi-racial/ethnic/Other & & $0.73(0.22-2.38)$ & $0.71(0.21-2.34)$ \\
\hline Age & $1.02(0.98-1.06)$ & $1.02(0.98-1.05)$ & $1.01(0.97-1.05)$ \\
\hline Female Gender & $1.55(0.86-2.78)$ & $1.39(0.76-2.53)$ & $1.40(0.76-2.58)$ \\
\hline < High school education & $1.01(0.49-2.07)$ & $1.16(0.55-2.46)$ & $0.82(0.36-1.90)$ \\
\hline Fair-to-poor health status & $2.37(1.20-4.67)$ & $2.22(1.11-4.46)$ & $2.11(1.04-4.28)$ \\
\hline
\end{tabular}

Multivariate models were adjusted for age and other variables associated with uncertainty at $\mathrm{P}<.20$ in bi-variate analysis including gender, education, and health status. Acculturation and language were excluded due to multi-collinearity as described in the methods.

${ }^{\dagger}$ Referent categories included: adequate literacy, White race/ethnicity, male gender, $\geq$ high school education, and good-to-excellent health status.

${ }^{*}$ Adjusted Odds Ratio (AOR) and 95\% Confidence Interval (CI) 